4 Shaw LJ, Berman DS, Maron DJ et al. Optimal medical therapy with or without percutaneous coronary intervention to reduce ischemic burden. Results from the clinical outcomes utilizing revascularization and aggressive drug evaluation (COURAGE) trial nuclear substudy. Circulation 2008;117:1283-91.

5 Hachamovitch R, Rozanski A, Shaw LJ et al. Impact of ischaemia and scar on the therapeutic benefit derived from myocardial revascularization vs. medical therapy among patients undergoing stress-rest myocardial perfusion scintigraphy. Eur Heart J 2011;32:1012-24.

6 Abraham A, Nichol G, Williams KA et al. ${ }^{18}$ F-FDG PET imaging of myocardial viability in an experienced center with access to $18 \mathrm{~F}-\mathrm{FDG}$ and integration with clinical management teams: the Ottawa-FIVE substudy of the PARR 2 trial. J Nucl Med 2010;51:567-74.

7 Einstein AJ, Knuuti J. Cardiac imaging: does radiation matter? Eur Heart J 2012;33:573-78.

8 Knuuti J, Saraste A, Kallio M, Minn H. Is cardiac magnetic resonance imaging causing DNA damage? Eur Heart J 2013;34:2337-9.

9 Brenner DJ. What we know and what we don't know about cancer risks associated with radiation doses from radiological imaging. Br J Radiol 2013;87:20130629.

10 Underwood SR, Godman B, Salyani S, Ogle J, Ell PJ. Economics of myocardial perfusion imaging in Europe: the EMPIRE Study. Eur Heart J 1999;20:157-66.

11 Shaw LJ, Hachamovitch R, Berman DS et al. The economic consequences of available diagnostic and prognostic strategies for the evaluation of stable angina patients: an observational assessment of the value of precatheterisation ischaemia. J Am Coll Cardiol 1999;33 661-9.

12 Thom H, West NEJ, Hughes V et al. Cost-effectiveness of initial stress cardiovascular MR, stress SPECT or stress echocardiography as a gatekeeper test, compared with upfront invasive coronary angiography in the investigation and management of patients with stable chest pain: mid-term outcomes from the CECaT randomised controlled trial. BMJ Open 2014;4:e003419.

\section{Steroid use for patients with brain metastases and spinal cord compression}

Editor - I read with interest 'Brain metastases' (Clin Med 2014;14:535-7) and 'Metastatic spinal cord compression: a rare but important complication of cancer' (Clin Med 2014;14:542-5). I would like to make a few further points regarding the use of steroids. Spencer et al advise highdose dexamethasone for patients with brain metastases, with a suggested regimen of $16 \mathrm{mg}$ daily, reducing to a maintenance dose of 2-4 mg daily. Dexamethasone provides symptomatic relief for patients with raised intracranial pressure from cerebral oedema but this relief reduces over time and undesirable side effects increase. Thus, ideally, the dose of dexamethasone should be discontinued after $2-4$ weeks. ${ }^{1}$ No benefit is seen in patients with asymptomatic brain metastases. ${ }^{2}$ Robson advises administering $16 \mathrm{mg}$ dexamethasone daily if metastatic cord compression is suspected, but eventual steroid reduction is not discussed. Following radiotherapy or surgery, steroids should be tailed off gradually and completely over 4-6 weeks, or to the lowest dose that maintains stability. Corticosteroids may result in a rapid improvement of neurological function but long-term benefit is limited, and there is no evidence that survival is improved. ${ }^{3}$ High-dose, long-duration treatment with corticosteroids causes significant side effects which can be debilitating and occasionally fatal. For those patients who do not proceed to surgery or radiotherapy, dexamethasone should be reduced gradually and stopped. We undertook an audit of the patients known to St Luke's Hospice in Plymouth in a six-month period this year $(n=1,152)$, and found one-third of them had taken steroids. Oncologists had prescribed steroids in nearly half of cases. $20 \%$ of patients were taking steroids for brain metastases and $10 \%$ for spinal cord compression. Steroid dose was not regularly reviewed and patients often remained on steroids for far too long, resulting in $40 \%$ of patients suffering sideeffects, most commonly proximal myopathy and peripheral oedema. $50 \%$ of patients were taking steroids until their death. GPs and palliative nurse specialists are often underconfident in reducing and stopping steroid courses and therefore clear guidance needs to be given to indicate duration of steroid course and plans for reduction.

\section{DR FAY MURRAY-BROWN ST4 palliative medicine, Hospiscare, Exeter, UK}

\section{References}

1 Vecht CJ, Hovestadt A, Verbiest HB, van Vliet JJ, van Putten WL. Dose effect relationship of dexamethasone on Karnofsky performance in metastatic brain tumours. A randomised study of doses of 4, 8 and 16mg per day. Neurology 1994;44:675-80.

2 Twycross R and Wilcock A (eds). Palliative care formulary, 4th edn. Nottingham: Palliativedrugs.com Ltd, 2011.

3 National Institute for Health and Clinical Excellence. Metastatic spinal cord compression: diagnosis and management of patients at risk of or with metastatic spinal cord compression. London: NICE, 2008.

\section{Response}

Editor - My thanks to Dr Murray-Brown for raising this important issue. In my article 'Metastatic spinal cord compression: a rare but important complication of cancer' I concentrated primarily on the presentation and initial management of these cases. In the short section on rehabilitation I did not discuss the reduction of steroids and I agree that this is a very important part of the management. In metastatic spinal cord compression patients the high dose steroids are used to reduce swelling and neurological symptoms whilst they start their definitive treatment. In our practice, once patients have commenced their fractionated radiotherapy treatment we reduce the steroids rapidly by half every two days. Most patients will have stopped taking their steroids just after their discharge on completion of radiotherapy treatment. Occasional patients require longer term treatment to control symptoms but this is kept at the lowest dose possible. If the patient deteriorates on reduction then higher doses are resumed short term to try to improve their symptoms.

I agree that patients who are not fit enough for definitive treatment, or who have received a single fraction of radiotherapy should have their steroids reduced gradually. Ideally they should be reduced gradually and then stopped over a 3-4 week period, or reduced and then maintained at the lowest possible dose at which their symptoms are controlled.

DR PETER ROBSON Consultant clinical oncologist, Clatterbridge Cancer Centre Liverpool, UK 